\title{
Integrando QR Code na educação na EJA: um projeto- piloto voltado para entendimento da língua portuguesa
}

\author{
Deise Luana Rosa Bastos ${ }^{1}$, Clevi Rapkiewicz ${ }^{1}$, Juçara Benvenuti ${ }^{1}$ \\ ${ }^{1}$ Colégio de Aplicação da Universidade Federal do Rio Grande do Sul \\ lulurbastos@gmail.com, clevi@ufrgs.br, benvenuti@ufrgs.br
}

\begin{abstract}
Integrating mobile devices on the teaching and learning process is a chalenge, particularly in the EJA (Education of Young and Adult) modality. In this article is presented and analyzed a pilot project developed in high school level of EJA from Colégio de Aplicação that integrates the Portuguese Language and Digital Culture areas. The subjects involved in the project integrated QR-Code for the encoding of portuguese language idiomatic expressions, making them avaiable for consultation for regular education students. The integration resulted positively in what concerns the possibilities of digital literacy of the subjects involved involving mobile devices as well as on the expansion of the dominance of linguistic aspects of the Portuguese Language.
\end{abstract}

Resumo. Integrar dispositivos móveis no processo de ensino e aprendizagem é um desafio, particularmente na modalidade de Educação de Jovens e Adultos (EJA). Neste artigo apresentamos e analisamos um projeto-piloto desenvolvido na EJA de Ensino Médio do Colégio de Aplicação integrando as áreas de Língua Portuguesa e Cultura Digital. Os sujeitos envolvidos no projeto integraram QR-Code para codificação de expressões da língua portuguesa, disponibilizando-os para consulta para alunos do ensino regular. A integração resultou positiva no que concerne às possibilidades de letramento digital dos sujeitos envolvidos envolvendo dispositivos móveis bem como na ampliação do domínio de aspectos linguísticos da Língua Portuguesa.

\section{Introdução}

A Educação de Jovens e Adultos (EJA) é uma modalidade prevista na Lei de Diretrizes e Bases (lei 9394/96), a qual destaca, no seu artigo 37: “A educação de jovens e adultos será destinada àqueles que não tiveram acesso ou continuidade de estudos no ensino fundamental e médio na idade própria" (BRASIL, 1996, p.15). Nessa modalidade, portanto, encontram-se sujeitos que construíram suas vidas sem concluir o currículo escolar básico, porém desenvolveram as mais variadas formas de conhecimento. Tratase de uma modalidade que atende a um público com características específicas, com saberes adquiridos no âmbito da família, do trabalho e demais esferas de socialização. Ou seja, muitas vivências adquiridas fora do espaço escolar.

No caso específico do grupo de EJA em que a pesquisa foi realizada consulta ao perfil dos alunos permite apontar que há alunos com formação e experiências de vida muito distintas: os mais jovens não chegaram a perder o vínculo com a escola, são 
V Congresso Brasileiro de Informática na Educação (CBIE 2016)

Anais do XXII Workshop de Informática na Escola (WIE 2016)

alunos que repetiram algumas séries por reprovação ou por desistência durante o ano letivo e terminaram por ficar fora da idade prevista para o curso regular. Quanto aos mais velhos, há casos entre dez e trinta anos de afastamento da escola. Além disso, a heterogeneidade também é visível no que se refere às ocupações que exercem, ou seja as turmas são constituídas por alunos que só estudam (menos de 10\%), alunos que trabalham por conta própria, outros são empregados de firmas terceirizadas que prestam serviço à Universidade, outros ainda são técnico-administrativos e alguns concursados.

Parece haver pouca literatura acerca da integração de recursos de Tecnologias de Informação e Comunicação (TICs) no processo de ensino e aprendizagem (Wehmann et al, 2015) desse público, o que não deixa de ser uma dupla exclusão - já foram alijados do ensino regular por diferentes razões, são pouco foco de integração de TIC. O que dirá, então, em termos do uso de dispositivos móveis?

As pesquisas indicam que há um grande uso de aparelhos celulares, inclusive nas faixas etárias relativas à EJA, a partir dos 18 anos até 60 anos ou mais. Segundo o indicador "Indivíduos que possuem telefone celular", retirado da pesquisa TIC Domicílios de 2014, 87\% da população de áreas urbanas possuem telefone celular, sendo que, na região Sul, o percentual é de 89. Além disso, segundo essa mesma pesquisa, 96\% da população que está cursando o Ensino Médio possui celular. Nas faixas etárias relativas à EJA, à partir dos 18 anos, esse número varia de 93 a $92 \%$ nas idades mais baixas e 85 a 64\% nas idades mais avançadas. Parece razoável, portanto, propor que o celular esteja presente na atividade pedagógica deste público.

Segundo outro dado, também retirado da pesquisa TIC Domicílios 2014, "Usuários de internet no telefone celular, por frequência de uso da internet no celular", que tem seu percentual sobre o total de pessoas que utilizaram internet no telefone celular nos últimos três meses, $85 \%$ da população de áreas urbanas utilizam com frequência, sendo que, na região Sul, o percentual é de 82 . Relativamente à parcela da população que está cursando o Ensino Médio, $86 \%$ utilizam com frequência a internet nos celulares. Nas faixas etárias relativas à EJA, esse número varia de 88 a $82 \%$ nas idades mais baixas e 76 a $70 \%$ nas idades mais avançadas.

No primeiro semestre de 2016, foi realizada uma pesquisa sobre uso das TIC em uma turma de primeiro semestre da EJA do Colégio de Aplicação da UFRGS (CAPUFRGS). Segundo essa pesquisa, 96.2\% dos alunos dessa turma, que têm idades entre 18 e 60 anos, possuem telefone celular e, dentro destes, $84.6 \%$ utilizam a internet nos celulares. Sendo assim, podemos supor que a utilização de celular com internet em sala de aula seria significativa para os alunos.

Neste contexto, buscando propiciar a alunos da EJA do CAP-UFRGS oportunidade de se apropriar da integração de dispositivos móveis na educação e, também, envolver licenciandos, este artigo relata e analisa um projeto-piloto do uso de celular integrando Cultura Digital e Língua Portuguesa. Para tanto, este artigo está organizado em 4 seções, além da presente introdução. Na seção 2 encontra-se o referencial teórico, dividido em duas partes, uma relativa à Cultura Digital e outra relativa à Língua Portuguesa. A metodologia utilizada está na seção 3. Na seção 4, analisamos os resultados para finalmente, na seção 5, apresentar algumas considerações finais. 
V Congresso Brasileiro de Informática na Educação (CBIE 2016)

Anais do XXII Workshop de Informática na Escola (WIE 2016)

\section{Referencial teórico}

\subsection{Cultura Digital e Computação ubíqua na EJA}

A Cultura Digital no contexto da EJA pode estar presente de várias formas. Se, por um lado, pode atuar como elemento integrador em outros componentes curriculares de forma a capacitar os alunos a usar recursos de TIC para desenvolverem pesquisas e expressarem seus conhecimentos através de diferentes mídias (texto, imagem, áudio, vídeo), também pode estar presente através de aspectos que dizem respeito a Cultura Digital em si.

Dois aspectos que dizem respeito a Cultura Digital em si são a inclusão digital e o letramento digital. A inclusão digital muitas vezes é considerada como a possibilidade de acesso às TIC por todas as camadas da sociedade. Porém, como chegamos em um momento em que a maior parte da população brasileira já tem esse acesso, é importante ressignificar esse termo. Segundo Teixeira et al. (2009), quando limitados o conceito de inclusão digital somente ao acesso a tecnologia, estamos esquecendo outras potencialidades do que os autores chamam de TR (tecnologias de rede).

(...) inclusão digital implica reconhecer-se como nó de uma rede de sentidos suportada pelas TRs, numa apropriação crítica, provisória e reflexiva desses fenômenos técnicos, numa dinâmica de (co)autoria, de partilha do conhecimento e de estabelecimento de processos colaborativos e comunicacionais, baseados no protagonismo, na valorização da própria cultura, no respeito à diversidade e na criação e manutenção de uma cultura de redes." (TEIXEIRA et al., 2009)

Torna-se necessário, portanto, ir além da inclusão, propondo o letramento digital buscando, segundo Xavier (2011), um conjunto de habilidades necessários para exercer a cidadania em meios digitais. O letramento digital não se limita pois a "alfabetizar" digitalmente (lembrando que alfabetizar está relacionado com o conhecimento do sistema de escrita, mas não necessariamente ao domínio do uso social dessa escrita, conforme apontado por Magda Soares). É necessário ensinar como utilizar os meios de navegação, as "infovias", da internet e de outros recursos de TIC disponíveis atualmente.

A promoção do letramento digital de alunos da EJA deve contemplar o uso de dispositivos móveis (m-learning), buscando-se a computação ubíqua na educação ( $u$ learning), conforme apontado por Santos (2013). Segundo a autora, computação ubíqua na educação é apontada como o uso de diversas tecnologias para promover as ações de aprendizagem, sendo que essas tecnologias estejam sempre disponíveis para o aluno. A possibilidade de aprender utilizando as TIC em qualquer lugar e a qualquer hora, se comunicar e compartilhar conteúdos em tempo real à longas distâncias com professores e colegas só tem a agregar na educação.

Porém, o contexto do Brasil dificulta com que isso seja uma realidade, ainda que, em termos de acesso a celulares, possamos falar em inclusão conforme os dados do CETIC apontados na introdução. Segundo Carvalho et al. (2016), as diferenças tecnológicas, educacionais, culturais, sociais e econômicas são barreiras para a 
V Congresso Brasileiro de Informática na Educação (CBIE 2016)

Anais do XXII Workshop de Informática na Escola (WIE 2016)

implementação do u-learning. São barreiras, pois, para o efetivo letramento digital.

Encontramos estudos relacionados em pelos menos dois artigos que discutem sobre a inserção de dispositivos móveis em sala de aula. Em Vieira e Conforto (2015) é discutida a possibilidade da perspectiva BYOD (Bring Your Own Device, ou "traga seu próprio dispositivo"). O aluno fica responsável por trazer seu dispositivo para a sala de aula para ser utilizado nas ações de aprendizagem. Diretamente relacionado, pois, com a ubiquidade tecnológica na educação.

Em outro artigo, Santos SANTOS et al (2013) discutem a mobilidade ( $m$ learning) e as vantagens do uso de dispositivos móveis em atividades de aprendizagem. Com o uso do smatphone, essa mobilidade é facilitada e o aluno pode utilizá-lo dentro da sala de aula e fora dela.

Considerando-se, pois, o apontado pelos autores mencionados, optamos pela abordagem BYOD com o objetivo de trazer para o aprendizado uma tecnologia que já conquistou seu espaço em sala de aula, porém de modo negativo. Os celulares costumam ser vilões em sala de aula pois tiram o foco dos educandos da aula, então unir essa tecnologia ao processo de aprendizagem pode diminuir a ocorrência dessa distração, dando um novo propósito à tecnologia.

\subsection{A Pesquisa Científica, a Língua Portuguesa e suas linguagens}

$\mathrm{Na}$ modalidade EJA, assim como no ensino regular, é importante que a educação também tenha os objetivos de formar para a continuidade dos estudos e para o exercício da cidadania, com a possibilidade de entrar ou progredir no mercado de trabalho. Tendo isso em vista, a educação para a pesquisa científica se torna importante, tanto para os estudantes que queiram continuar sua formação quanto para os que tem foco no mercado de trabalho.

No aspecto acadêmico, para aqueles que desejam seguir esse caminho, a pesquisa científica tem sua importância na produção de conhecimento. As pesquisas científicas acadêmicas têm como objetivo contribuir para o avanço da ciência em determinada área e para a sociedade, com pesquisas que possam contribuir para o desenvolvimento desta. Ainda que não necessariamente seja essa a questão na educação básica (contribuir para o desenvolvimento científico em si) é importante educar para o pensamento científico.

No mercado de trabalho, nota-se uma exigência maior para que o profissional desenvolva além de conhecimentos teóricos. Segundo Campos, Santos e Santos (2009), o mercado de trabalho vem exigindo conhecimentos práticos que busquem produção de novas ideias e conhecimentos. Para os estudantes dessa modalidade que desejem crescer no mercado de trabalho, a pesquisa científica também se mostra importante. Oportunizar a alunos da EJA, portanto, oportunidade de desenvolver investigações, não necessariamente científicas, mas que sigam o ciclo de ter um problema ou questão norteadora e buscar respostas é, também, uma forma de contribuir para empregabilidade deles.

Outra questão importante, tanto para aqueles alunos da EJA que buscam melhor inserção no mercado de trabalho quanto para aqueles que pretendem ampliar seus 
V Congresso Brasileiro de Informática na Educação (CBIE 2016)

Anais do XXII Workshop de Informática na Escola (WIE 2016)

estudos (ou que almejam ambas as coisas), o conhecimento adequado da Língua Portuguesa é necessário.

A Base Nacional Comum aponta para a necessidade de discutir o papel do Ensino Médio na formação dos sujeitos, já que essa etapa escolar não é independente, mas complementar às anteriores. Por isso a constituição da nova BNC não se distingue da Lei de Diretrizes e Bases da Educação 9394/96, que em seu artigo 35 diz a finalidade do Ensino Médio:

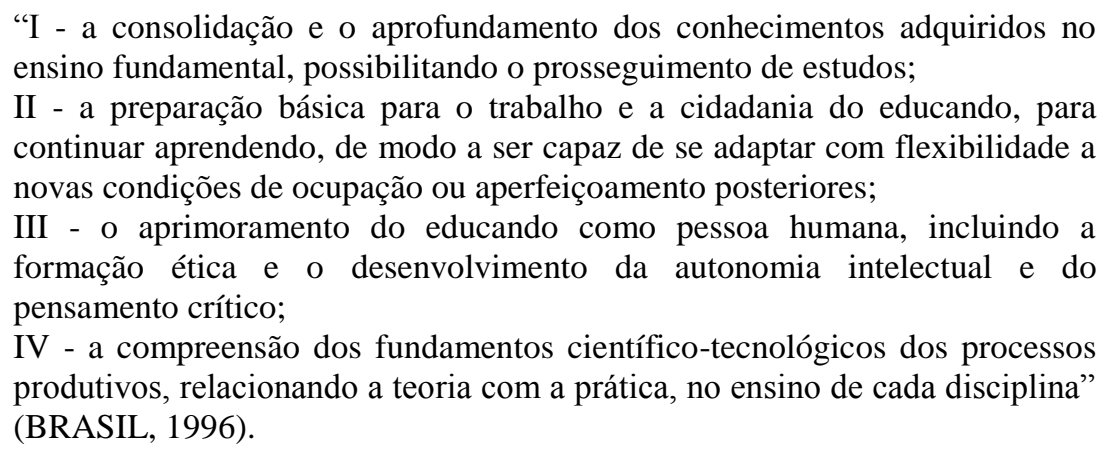
produtivos, relacionando a teoria com a prática, no ensino de cada disciplina" (BRASIL, 1996).

Assim, o planejamento dos conteúdos do curso de EJA do CAP prevê a vinculação das temáticas com a vida dos alunos. Através da interdisciplinaridade entre Língua Portuguesa e Cultura Digital, desenvolvemos a proposta que une estudos linguísticos com as TIC tendo como objeto de estudo expressões idiomáticas. As expressões idiomáticas são recorrentes na vida diária e ocorrem quando um termo ou frase assume significado diferente daquele que as palavras teriam isoladamente. Assim, a interpretação é captada globalmente, sem necessidade da compreensão de cada uma das partes.

As expressões são usadas no noticiário da televisão, em anúncios dos jornais, no rádio, na tv, em discursos políticos, campanhas eleitorais, em filmes, em letras de música, na literatura, etc, por isso o aluno já está familiarizado com elas. Partir de coisas conhecidas para buscar novos conhecimentos é uma forma de valorização dos saberes que o aluno adulto já adquiriu em sua vida, uma das metas da EJA.

É importante verificar que o uso das expressões idiomáticas não se restringe a uma determinada camada social. Elas são uma parte importante da comunicação informal, tanto escrita como falada, e também são usadas frequentemente no discurso e na correspondência formal. Elas podem enriquecer a frase ou enfatizar algum aspecto com humor ou ironia. Por exemplo: "acabar em pizza". O significado de uma por uma das palavras teria um significado diferente daquele desejado por quem usa toda a expressão: que é usada quando uma situação não resolvida acaba encerrada.

Associar os recursos de linguagem com a tecnologia, para pesquisas e/ou para desenvolver habilidades como o uso do QRCode, pode representar um recurso para estimular a aprendizagem. O grupo de professores do colégio busca incentivar o uso dos recursos disponíveis aos alunos, que passam a funcionar como auxiliares no desenvolvimento de habilidades e de conhecimento, hoje exigidos pela sociedade. 
V Congresso Brasileiro de Informática na Educação (CBIE 2016)

Anais do XXII Workshop de Informática na Escola (WIE 2016)

\section{Objetivos, materiais e métodos}

O objetivo principal do projeto foi propiciar a alunos da EJA CAP-UFRGS oportunidade de se apropriar da integração de dispositivos móveis na educação e, também, envolver licenciandos em Letras da universidade na mediação pedagógica integrando Cultura Digital e Língua Portuguesa. Foi priorizado o uso de smartphones, buscando reverter a concepção de que eles são vilões em sala de aula. Incorporar o dispositivo móvel na ação pedagógica nas atividades em sala de aula é uma forma de evitar que eles o usem para atividades alheias ao contexto educacional durante as aulas.

Considerando-se ser um projeto-piloto, optou-se por não realizar a atividade com toda uma turma. O Projeto Pedagógico da EJA CAP-UFRGS contempla o desenvolvimento de Projetos de Investigação (PI). São projetos em que os alunos pesquisam sobre assuntos de seu interesse e trabalham de uma forma livre com esses assuntos, mediante orientação de professores. Os professores oferecem turmas pequenas com assuntos de suas áreas e os alunos escolhem o assunto de sua preferência. No final da pesquisa, eles escolhem como irão apresentar seus trabalhos para o conjunto de alunos da EJA da escola, sendo esta uma atividade de finalização do semestre. Os PI apresentados são avaliados e constituem parte do processo avaliativo do aluno para progredir para outro ano da EJA.

Ofertar PI para alunos da EJA se sustenta na proposta de educar pela pesquisa (MORAES, GALIAZZI e RAMOS, 2004), buscando trazer para o debate as concepções e conhecimentos dos participantes sobre o tema tratado. Implica no desenvolvimento de uma sequência de ações que permita um ciclo de questionamento reconstrutivo composto de três elementos que se alternam: questionamento, construção de argumentos, comunicação. No primeiro momento, o sujeito se manifesta quanto ao tema abordado, suas visões, concepções, conhecimentos prévios. No segundo momento, os conhecimentos e concepções prévias são validados ou não através de pesquisa e de diálogo mediado pelo orientador. A divulgação dos novos conhecimentos e concepções, em um terceiro momento, deve ultrapassar o mini-grupo sujeitoorientador de forma a possibilitar a análise crítica por outros sujeitos.

Nesse contexto, foi oferecido no primeiro semestre de 2016 o PI chamado "QR Code - (De)codificando a nossa língua". A proposta do PI proporciona as condições para a investigação da língua portuguesa, mais especificamente sobre as expressões idiomáticas da língua, e utilizar a tecnologia QR Code para divulgar as produções realizadas pelos alunos.

Participou desse PI um aluno do segundo ano do Ensino Médio, do sexo masculino com 19 anos. No geral, o aluno possui conhecimento alto em funcionalidades básicas do computador e celular. $\mathrm{O}$ aluno possui celular com acesso à internet e realiza esse acesso no dispositivo, quando uma rede móvel está disponível. Ou seja, não tem acesso a internet através de pacote de serviços mediante pagamento, sim através da rede sem fio da escola. O sujeito da pesquisa aderiu ao projeto voluntariamente entre as várias opções apresentadas pela equipe de professores da EJA.

A sequência de ações desenvolvidas entre o sujeito e o orientador, buscando constituir um ciclo de questionamento reconstrutivo está descrita na Tabela 1. 
V Congresso Brasileiro de Informática na Educação (CBIE 2016)

Anais do XXII Workshop de Informática na Escola (WIE 2016)

Tabela 1. Ciclo de questionamento reconstrutivo aplicado

\begin{tabular}{|c|c|c|}
\hline Item & Atividade & Descrição da atividade \\
\hline 1 & Apresentação do projeto & $\begin{array}{l}\text { Apresentação da proposta para o conjunto de alunos da EJA } \\
\text { e inscrição de aluno (voluntária) }\end{array}$ \\
\hline 2 & $\begin{array}{l}\text { Levantamento de } \\
\text { conhecimentos prévios }\end{array}$ & $\begin{array}{l}\text { Interação com o aluno, buscando identificar conhecimentos } \\
\text { relacionados ao projeto, análise do perfil de inclusão digital }\end{array}$ \\
\hline 3 & $\begin{array}{l}\text { Apresentação do conteúdo } \\
\text { QR Code }\end{array}$ & $\begin{array}{l}\text { Apresentação do que é QR Code e atividades para praticar } \\
\text { o seu uso }\end{array}$ \\
\hline 4 & $\begin{array}{l}\text { Discussão sobre } \\
\text { expressões idiomáticas }\end{array}$ & $\begin{array}{l}\text { Discutir sobre a proposta do PI em si, com a pesquisa sobre } \\
\text { expressões idiomáticas }\end{array}$ \\
\hline 5 & $\begin{array}{l}\text { Discussão sobre a fase } \\
\text { comunicação }\end{array}$ & $\begin{array}{l}\text { Analisar junto com os alunos a melhor forma de apresentar } \\
\text { os projetos ao fim do semestre (vídeo, slides, blog...) }\end{array}$ \\
\hline 6 & $\begin{array}{l}\text { Vários encontros para } \\
\text { criação dos conteúdos, } \\
\text { códigos e cartazes }\end{array}$ & $\begin{array}{l}\text { Os cartazes fazem parte da proposta do projeto. Essa parte } \\
\text { serve para divulgar a pesquisa dos alunos, incentivar o uso } \\
\text { do QR Code e, também, para ser usada como aprendizado } \\
\text { do QR Code. Pode ser usada também na apresentação do } \\
\text { trabalho final, caso seja do interesse dos alunos mostrar essa } \\
\text { parte do projeto. }\end{array}$ \\
\hline 7 & $\begin{array}{l}\text { Discussão de textos sobre } \\
\text { pesquisa científica }\end{array}$ & $\begin{array}{l}\text { Refletir e discutir sobre pesquisa científica, trazendo para a } \\
\text { realidade da EJA }\end{array}$ \\
\hline 8 & Culminância do projeto & $\begin{array}{l}\text { Fechamento do ciclo com apresentação dos resultados da } \\
\text { pesquisa e da construção dos cartazes para os outros alunos } \\
\text { da EJA e equipe de professores. }\end{array}$ \\
\hline 9 & Encontro de avaliação & $\begin{array}{l}\text { Discussão com o aluno e professores orientadores para ver } \\
\text { o que pode ser modificado na proposta, a partir desse } \\
\text { projeto piloto }\end{array}$ \\
\hline
\end{tabular}

Esse conjunto de ações visou introduzir o contato com recursos tanto de hardware quanto de softwares ou serviços no celular ou online, os quais estão sintetizados na Tabela 2.

Tabela 2. Recursos de TIC usados no projeto

\begin{tabular}{|c|c|c|}
\hline Item & Aplicativo ou recurso & Função do recursos no projeto \\
\hline 1 & Computador & $\begin{array}{c}\text { Pesquisa, criação de um blog no Pinterest, compartilhamento de } \\
\text { materiais no Google Drive, criação de cartazes, utilização de } \\
\text { site gerador de códigos QR no período em que a escola não } \\
\text { possuía rede wi-fi utilizável, leitura dos códigos QR criados } \\
\text { utilizando webcam. }\end{array}$ \\
\hline 2 & Celular smartphone & Acesso à rede wi-fi da escola, uso do aplicativo leitor e gerador \\
de códigos QR.
\end{tabular}


V Congresso Brasileiro de Informática na Educação (CBIE 2016)

Anais do XXII Workshop de Informática na Escola (WIE 2016)

\section{Resultados}

Analisamos os resultados do projeto-piloto de três formas. Primeiro, do ponto de vista da inclusão e letramento digital tanto do aluno quanto da licencianda em Letras envolvida no projeto. Segundo, relativo a produção de materiais de diferentes tipos pelo aluno. Terceiro, da ampliação de conhecimentos da língua portuguesa por parte do aluno e sua aplicabilidade na vida cotidiana.

No primeiro aspecto da análise dos resultados, referente ao letramento digital do aluno, comparamos o estado em que ele se encontrava digitalmente e onde se encontra agora. $\mathrm{O}$ aluno já possuía muito conhecimento em relação às tecnologias utilizadas, não foi preciso dedicar tempo a esse aprendizado. Porém, saber usar não significa saber aproveitar todos os recursos, especialmente quando se trata de pesquisa. $\mathrm{O}$ aluno apresentou uma evolução significativa no seu método de pesquisa, comparando os primeiros encontros dedicados a isso com o último. Para ele, essa união de Língua Portuguesa e tecnologias móveis é útil, pois a tecnologia é de mais fácil acesso que livros e materiais impressos.

Também neste primeiro aspecto, referente à experiência da licencianda em Letras, a mesma declara ter tido um crescimento nas questões de tecnologia. Segundo ela, a união de ensino de Língua Portuguesa e recursos digitais traz benefícios para os alunos que têm dificuldades em encontrar materiais impressos, fato muito comum na era da tecnologia. Para realizar a pesquisa, ela também teve que aprender a utilizar os recursos tecnológicos apresentados para o aluno, declara, nesse contexto, que evoluiu com o aluno. Observar, pois, que o processo de mútua aprendizagem entre mediadoreducador e aluno se fez presente, tornando o processo significativo para ambos.

Relativamente à produção de materiais pelo aluno, foi produzido por ele, com orientação da licencianda, um blog na plataforma Pinterest (Figura 1a). Nesse blog, foram postadas suas produções textuais realizadas em sala de aula, exemplificada na Figura 1b.

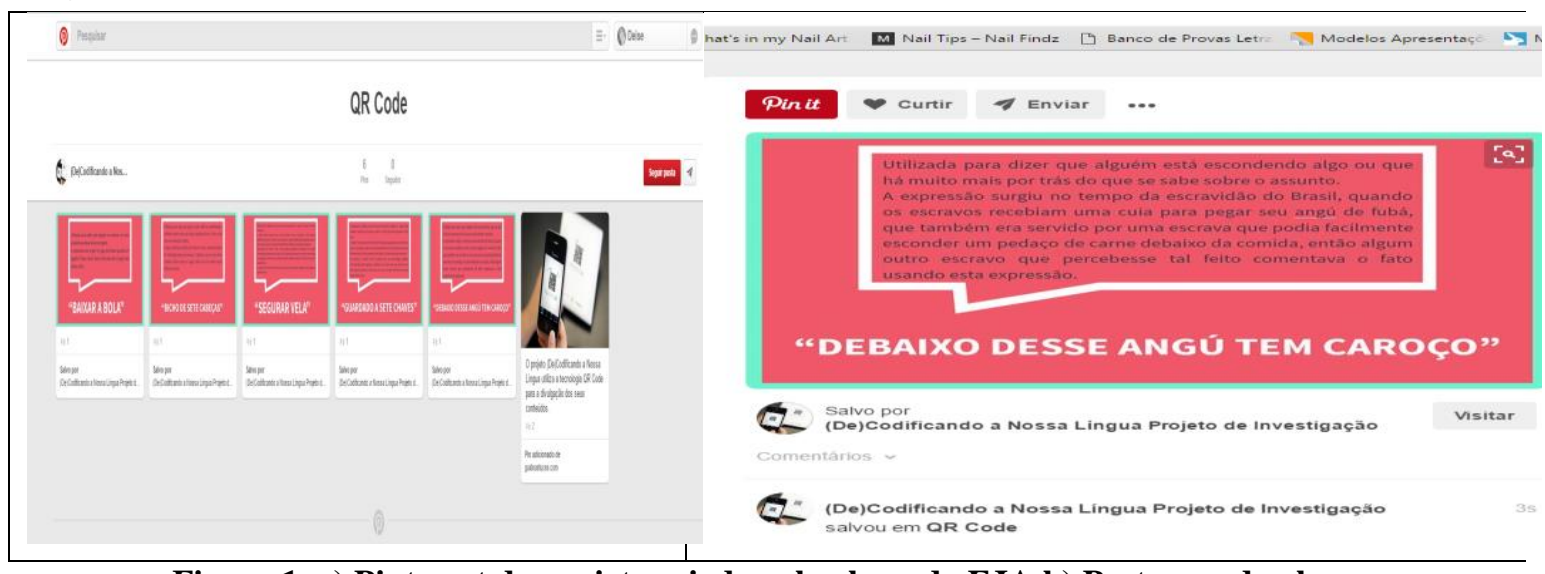

Figura 1. a) Pinterest do projeto criado pelo aluno da EJA b) Postagem do aluno

Após essas produções textuais serem postadas no blog, o aluno criou cartazes com códigos QR que levavam a elas para serem dispostos nos corredores da escola e serem acessados por alunos do ensino regular. Essa ação dá visibilidade para alunos da EJA, que já chegam à escola em horários em que não há mais alunos do regular. 
V Congresso Brasileiro de Informática na Educação (CBIE 2016)

Anais do XXII Workshop de Informática na Escola (WIE 2016)

Também chama a atenção de alunos do regular que pessoas que muitas vezes são invisíveis do ponto de vista educativo por atuarem nas funções-meio da escola (vigilância, limpeza) também fazem parte da comunidade escolar, uma vez que parte do público da EJA são os trabalhadores terceirizados da universidade.

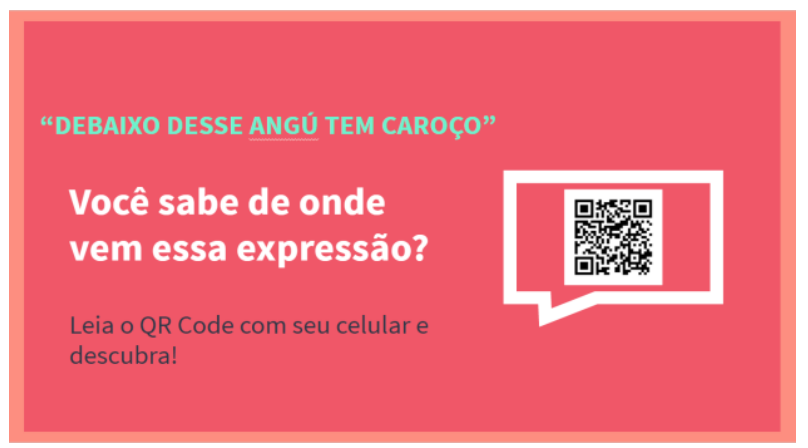

Figura 2. Cartaz com QR Code direcionando à postagem no Pinterest

Foram proporcionados os modelos tanto de post no Pinterest quanto de cartaz, para otimizar o tempo das aulas. Os modelos foram compartilhados com o aluno pelo Google Drive e ele fazia as modificações de acordo com suas pesquisas e produções textuais e de acordo com suas preferências estéticas. Foram produzidos 5 posts com produções textuais do aluno no Pinterest e 5 cartazes com QR Codes referentes a cada uma das produções. Os cartazes foram expostos em forma de totem em um dia de entrega de pareceres na escola. Assim, tanto alunos como pais tiveram acesso ao resultado do projeto.

Referente ao terceiro aspecto da análise dos resultados, sobre os conhecimentos da língua portuguesa desenvolvidos pelo aluno, houve um grande interesse por parte dele em se aprofundar na pesquisa e foram pesquisadas muitas expressões idiomáticas por ele. Essas expressões pesquisadas foram listadas e foi aprofundada a pesquisa em algumas delas, que o aluno teve mais interesse. Como futura professora de línguas, a licencianda que mediou o projeto declara que lhe foram abertas muitas possibilidades. $\mathrm{O}$ interesse do aluno a fez considerar o uso de TIC para o ensino tanto de língua portuguesa como de língua estrangeira, ou seja, para o desenvolvimento de competências na área da comunicação usando diferentes línguas.

\section{Considerações Finais}

A integração dos componentes curriculares de Língua Portuguesa e Cultura Digital em um projeto-piloto oferecido para os alunos de Ensino Médio da modalidade EJA prezou pelo aprendizado sobre a língua portuguesa buscando o letramento digital dos alunos por meio da inserção de TIC em sala de aula. O projeto atingiu seu objetivo de limitar o uso de smartphones para atividades alheias ao contexto de sala de aula, além de ter promovido a inclusão digital do aluno por meio do acesso à rede wi-fi do colégio. Ultrapassando a mera questão do acesso, ocorreu letramento na medida em que a tecnologia foi resignificada para alo útil, com sentido para o aluno - fazendo pois o uso social da tecnologia, como o letrado faz uso social da escrita, ampliando a abordagem da alfabetização.

Nos deparamos com algumas dificuldades de estrutura, como a falta se sala 
V Congresso Brasileiro de Informática na Educação (CBIE 2016)

Anais do XXII Workshop de Informática na Escola (WIE 2016)

específica para a realização do projeto e passagem por um período sem rede sem fio de qualidade. Apesar disso, foi possível realizar e atingir os objetivos esperados na idealização do projeto, superando as expectativas do sujeito da pesquisa, que se mostrou muito animado em continuar a pesquisa e, talvez, expandir o foco dela.

Observa-se que há potencial para ampliar a ação, tanto no contexto da própria integração de Língua Portuguesa com Cultura Digital quanto em outros componentes curriculares. No caso da Língua Portuguesa já foram iniciadas ações com alunos de terceiro ano do ensino médio, também na modalidade EJA, ano letivo no qual se encontra o aluno que participou do projeto piloto, propiciando ao mesmo divulgar os conhecimentos adquiridos no PI entre seus pares.

Pode ser interessante inserir um contador de acessos no blog para acompanhar em que medida as postagens feitas despertaram a curiosidade da comunidade escolar.

\section{Referências}

Brasil. (1996) Lei de Diretrizes e Bases da Educação n 9.394, de 20 de dezembro de 1996", Estabelece as diretrizes e bases da educação nacional.

Campos, F. G. G.; Santos, R. R. e Santos, F. C. P. (2009) A importância da pesquisa científica na formação professional dos alunos do curso de Educação Física do UNILESTEMG, MOVIMENTUM - Revista Digital de Educação Física, v.4, n.2.

Carvalho, A. C. P. L. et al. (2016) Grandes Desafios da Pesquisa em Computação no Brasil - 2006 - 2016,: Relatório sobre o Seminário realizado em 8-9 maio de 2006.

CETIC. TIC Domicílios 2014. Disponível em <http://www.cetic.br/pesquisa/domicilios/indicadores> Acesso em 25 de maio de 2016.

Compagnoni, M. e Conforto, D. (2015) Aprendizagem Móvel e Multimídia: a produção de material pedagogica na perspectiva BYOD, XXI Workshop de Informática na Escola - WIE. Disponível em ie.org/pub/index.php/sbie/article/view/2483> Acesso em 19 de abril de 2016.

Moraes, R.; Galiazzi, M. C. e Ramos, M. G. (2004) Pesquisa em sala de aula: fundamentos e pressupostos, Moraes, R. e Lima, V. M. R. (Orgs.). Pesquisa em Sala de Aula: tendências para a Educação em Novos Tempos. $2^{a}$ Ed, EDIPUCRS, p. 9-24.

Santos, N. S. R. (2013) M-Roamin - Um Modelo para Representação de Objetos de Aprendizagem Multimodais Interativos. Tese de doutorado, Programa de PósGraduação em Informática na Educação (PGIE), UFRGS, 2013.

Teixeira, A. e Marcon, K. (2009) Inclusão digital: experiências, desafios e perspectivas. XXI WIE Disponível em <http://usuarios.upf.br/ teixeira/livros/inclusao_digital.pdf>.

Weihmann, G. et al. (2015) Integrando tecnologias digitais na Educação de Jovens e Adultos: análise das publicações no Brasil, XXI - WIE. Disponível em 〈http://www.br-ie.org/pub/index.php/wie/article/view/5090> Acesso em 26 de maio de 2016.

Xavier, A. (2011) Letramento digital e ensino, Disponível em $<$ https://www.ufpe.br/nehte/artigos/Letramento\%20digital\%20e\%20ensino.pdf $>$ Acesso em 26 de maio de 2016. 